\title{
Millimeter Wave Fabry-Perot Resonator Antenna Fed by CPW with High Gain and Broadband
}

\author{
Xue-Xia Yang, Guan-Nan Tan, Bing Han, and Hai-Gao Xue \\ School of Communication and Information Engineering, Shanghai University, Shanghai 200072, China \\ Correspondence should be addressed to Xue-Xia Yang; yang.xx@shu.edu.cn
}

Received 27 January 2016; Revised 4 April 2016; Accepted 20 April 2016

Academic Editor: Shah N. Burokur

Copyright ( 2016 Xue-Xia Yang et al. This is an open access article distributed under the Creative Commons Attribution License, which permits unrestricted use, distribution, and reproduction in any medium, provided the original work is properly cited.

\begin{abstract}
A novel millimeter wave coplanar waveguide (CPW) fed Fabry-Perot (F-P) antenna with high gain, broad bandwidth, and low profile is reported. The partially reflective surface (PRS) and the ground form the F-P resonator cavity, which is filled with the same dielectric substrate. A dual rhombic slot loop on the ground acts as the primary feeding antenna, which is fed by the CPW and has broad bandwidth. In order to improve the antenna gain, metal vias are inserted surrounding the F-P cavity. A CPW-to-microstrip transition is designed to measure the performances of the antenna and extend the applications. The measured impedance bandwidth of $S_{11}$ less than $-10 \mathrm{~dB}$ is from 34 to $37.7 \mathrm{GHz}(10.5 \%)$, and the gain is $15.4 \mathrm{dBi}$ at the center frequency of $35 \mathrm{GHz}$ with a $3 \mathrm{~dB}$ gain bandwidth of 7.1\%. This performance of the antenna shows a tradeoff among gain, bandwidth, and profile.
\end{abstract}

\section{Introduction}

Millimeter wave communication systems not only have high data rate and small size but also provide an access to the less crowded spectrum. They have been suggested to be applied in the local area networks [1-3], 5G networks (next generation of cellular mobile network with improved data rates) [4, 5], wireless power transmission systems [6], and so on. As the key components of these systems, millimeter wave antennas with high gain and planar structure have been investigated recently. Microstrip antennas have been good candidates in normal wireless systems because of their low profile, low cost, and easy integration. However, the gains of the microstrip antenna arrays at millimeter wave bands are limited due to the higher losses of feed networks. Reflector antennas have high gain but the three-dimensional structures limit the applications [7].

The Fabry-Perot (F-P) structure was firstly suggested to be applied in the antenna design in 1956 [8]. Over the last few years, various F-P antennas have been reported [9-20], which are listed in Table 1 . The antennas in [9-16] have the air layers so the heights are all higher than $0.5 \lambda_{0}$. The antenna in [10] obtains a gain of $22.7 \mathrm{dBi}$ and $3 \mathrm{~dB}$ gain bandwidth of $13.2 \%$; however, four substrate layers are used and the height reaches
$1.67 \lambda_{0}$. In [17], the artificial magnetic conductor (AMC) replaces the ground conductor to design the F-P antenna. The height of the air layer is reduced to $\lambda_{0} / 4$ and the gain of the antenna is $19 \mathrm{dBi}$. However, the structure is complicate and the $3 \mathrm{~dB}$ gain bandwidth is only $2 \%$. Practically, it is difficult to accurately fix the height of the air layer in millimeter wave band designs, which would influence antenna performance obviously. In order to enhance the robustness and lower the profile of the F-P antenna, the dielectric layers substitute for the air layers in some designs [18-20]. Although the height of these antennas are all lower than $0.25 \lambda_{0}$, the $3 \mathrm{~dB}$ gain bandwidths are all narrower than $2.5 \%$. Among these reported F-P antennas, only several antennas operate at millimeter waves [13-16, 20]. A $2 \times 2$ array is applied as the primary feeding antenna for the F-P antenna at $60 \mathrm{GHz}$ [13]. The measured gain is $15.2 \mathrm{dBi}$ while the $3 \mathrm{~dB}$ gain bandwidth is only $0.5 \%$. In [14], the $94 \mathrm{GHz}$ F-P antenna has a threedimensional PRS cover. Although the height is $1.02 \lambda_{0}$, the gain is $13 \mathrm{dBi}$ and the $3 \mathrm{~dB}$ gain bandwidth is only $1 \%$. A dualpolarized F-P antenna operated at $35 \mathrm{GHz}$ is reported in [15]. The height is $0.67 \lambda_{0}$, and the $3 \mathrm{~dB}$ gain bandwidth is $7.1 \%$. The gains are $16.1 \mathrm{dBi}$ and $15.1 \mathrm{dBi}$ for the two polarizations, respectively. Reference [16] presents a V-band F-P antenna with an all-metal cap as the PRS. The height is $0.52 \lambda_{0}$, and 
TABLE 1: Performances of the published F-P antennas.

\begin{tabular}{|c|c|c|c|c|c|}
\hline Reference & $f(\mathrm{GHz})$ & $\begin{array}{l}\text { Height of air } \\
\text { layer }\end{array}$ & $\begin{array}{c}\text { Substrate layers/antenna } \\
\text { height }\end{array}$ & $\begin{array}{c}3 \mathrm{~dB} \text { gain } \\
\text { bandwidth }\end{array}$ & Gain $(\mathrm{dBi})$ \\
\hline [9] & 14 & $\lambda_{0} / 2$ & $3 / 0.9 \lambda_{0}$ & $5.7 \%$ & $19(2 \times 2$ array $)$ \\
\hline$[10]$ & 12 & $\lambda_{0} / 2$ & $4 / 1.67 \lambda_{0}$ & $13.2 \%$ & $22.7(4 \times 8$ array $)$ \\
\hline [11] & 14 & $\lambda_{0} / 2$ & $2 / \lambda_{0}$ & $6 \%$ & 17.44 \\
\hline$[12]$ & 10 & $\lambda_{0} / 2$ & $3 / 0.55 \lambda_{0}$ & $28 \%$ & 13.8 \\
\hline$[13]$ & 60 & $\lambda_{0} / 2$ & $3 / 0.52 \lambda_{0}$ & $0.5 \%$ & $15.2(2 \times 2$ array $)$ \\
\hline$[14]$ & 94 & $\lambda_{0} / 2$ & Nonplanar/1.02 $\lambda_{0}$ & $1 \%$ & 13 \\
\hline$[15]$ & 35 & $\lambda_{0} / 2$ & $3 / 0.67 \lambda_{0}$ & $7.1 \%$ & $16.1,15.1$ \\
\hline$[16]$ & 63 & $3 \lambda_{0} / 10$ & $2 / 0.52 \lambda_{0}$ & $4.3 \%$ & 11 \\
\hline$[17]$ & 14 & $\lambda_{0} / 4$ & $2 / 0.3 \lambda_{0}$ & $2 \%$ & 19 \\
\hline$[18]$ & 10 & No & $3 / 0.11 \lambda_{0}$ & $2 \%$ & 12.5 \\
\hline$[19]$ & 10 & No & $3 / 0.12 \lambda_{0}$ & $2.3 \%$ & 13.5 \\
\hline$[20]$ & 44 & No & $1 / 0.23 \lambda_{0}$ & $1 \%$ & 14 \\
\hline This work & 35 & No & $2 / 0.38 \lambda_{0}$ & $7.1 \%$ & 15.4 \\
\hline
\end{tabular}

the measured gain is only $11 \mathrm{dBi}$ with the $3 \mathrm{~dB}$ gain bandwidth of $4.3 \%$. In [20], a Q-band F-P antenna is designed with the gain of $14 \mathrm{dBi}$ and the height of $0.23 \lambda_{0}$. However, the $3 \mathrm{~dB}$ gain bandwidth is only $1 \%$.

In this paper, a novel millimeter wave F-P antenna is proposed and designed at $35 \mathrm{GHz}$. The F-P resonator cavity is composed of the partially reflective surface (PRS) cover and the ground, which is filled with the same dielectric substrate. The primary feeding antenna is a dual rhombic slot loop fed by the CPW line, which has broadband performance. The CPW feedline is employed for its low loss property in millimeter wave band. In order to test the performances of the antenna and extend the applications, a CPW-to-microstrip transition is designed. The performance of proposed antenna has a tradeoff among the high gain, broad bandwidth, and low profile. Table 1 gives a comparison between the reported F-P antennas and this work.

\section{Antenna Design}

2.1. Antenna Structure. The geometrical structure of the proposed F-P antenna fed by the CPW is shown in Figure 1. The antenna consists of two layers of substrates, layer \#1 and layer \#2 with the thicknesses of $H_{1}$ and $H_{2}$, respectively. The two substrate layers are all Rogers 5880 with the relative permittivity of 2.2 and the tangential loss of 0.0009 . Layer $\# 1$ is the PRS substrate support and acts as the Fabry-Perot resonator. The PRS consists of $9 \times 9$ hexagon hoop cells as shown in Figure 1(a). The period distance of the PRS cells is $T_{f}$. Layer \#2 is for the primary feeding antenna, which is a dual rhombic slot loop with the length of $L_{1}$ and width of $W_{1}$ and is printed on the bottom of layer \#2 as shown in Figure 1(b). The dual rhombic slot loops are diagonally fed by a CPW feedline with the metal trace width of $W_{2}$ and the gap of $g$. The stub length of $L_{2}$ influences the antenna's impedance match performance. The detailed sizes of the dual rhombic slot loops are shown in Figure 1(c). The metal vias from the top metal layer to the bottom one surround the PRS structure, which is shown in Figures 1(a) and 1(b).

2.2. PRS Cell Design. The PRS on the top layer of substrate layer \#1 and the ground plane on the bottom of layer \#2 form the F-P cavity. The electromagnetic wave in this cavity is excited by the dual rhombic loop-slot. According to the early work of Von Trentini [8], a simple optical ray model can be used to analyze the antenna. The analysis is similar to the resonant optical cavity theory. With the multiple reflection of the wave emitted by the PRS, a resonance would be achieved when the reflected waves are in phase after one cavity roundtrip. Thus, a highly directive beam can be obtained at the designed frequency. by

The resonant condition of this F-P antenna can be written

$$
\varphi_{g}+\varphi_{r}-\frac{4 \pi h}{\lambda}=2 N \pi, \quad N=0, \pm 1, \pm 2,
$$

where $h$ is the height between the PRS and the ground, $\varphi_{g}$ is the reflection phase of the metal ground plane, $\varphi_{r}$ is the reflection phase of the PRS, and $\lambda$ is the operation wavelength in the substrate, which is different from the free space wavelength $\lambda_{0}$ in conventional air-filled F-P antennas resonant condition. $\lambda$ is shorter than $\lambda_{0}$, so it can be seen from (1) that the height $h$ of the proposed F-P cavity is smaller than the conventional air-filled ones.

Assuming the size of the PRS to be infinite, the increased directivity of the FPCA can be calculated by

$$
D_{\text {inc }}=10 \times \log \frac{1+R}{1-R}
$$

where $D_{\text {inc }}$ is the increased directivity comparing with the primary antenna and $R$ is the reflection magnitude of the PRS. In order to obtain high directivity, the PRS with high reflection magnitude is desired. 


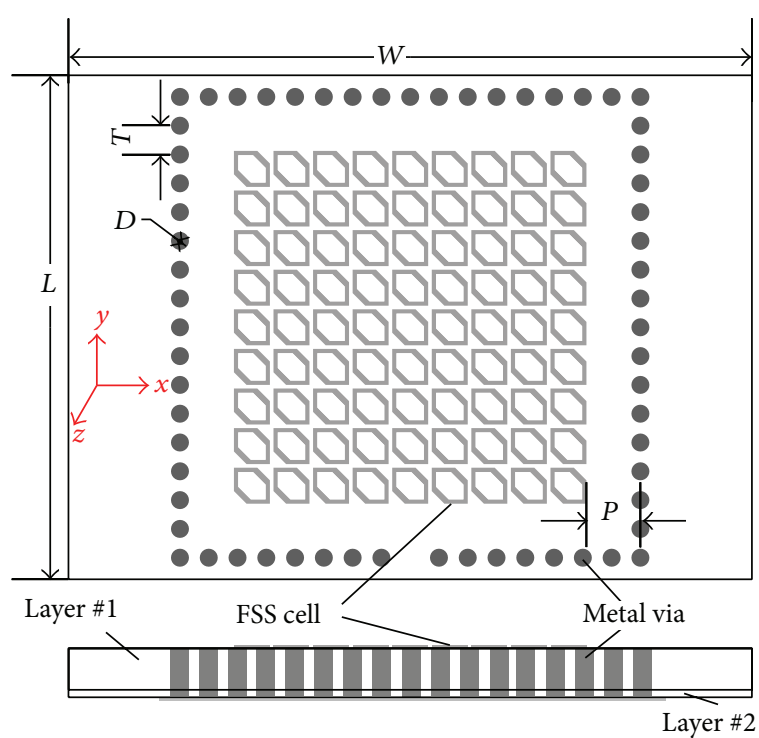

(a)

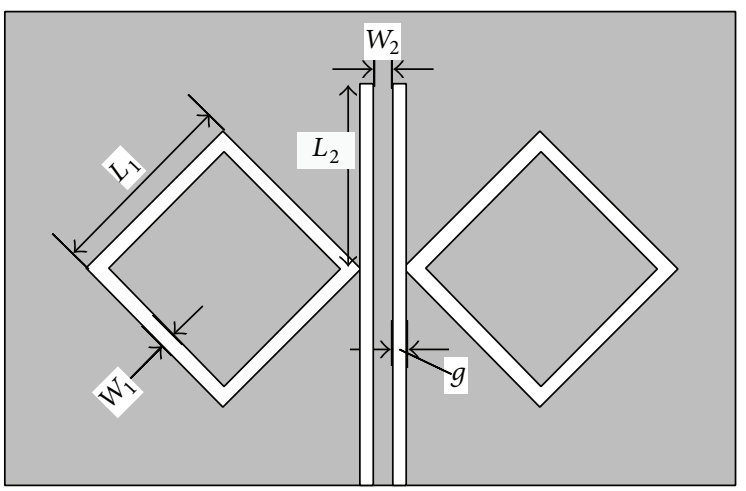

(c)

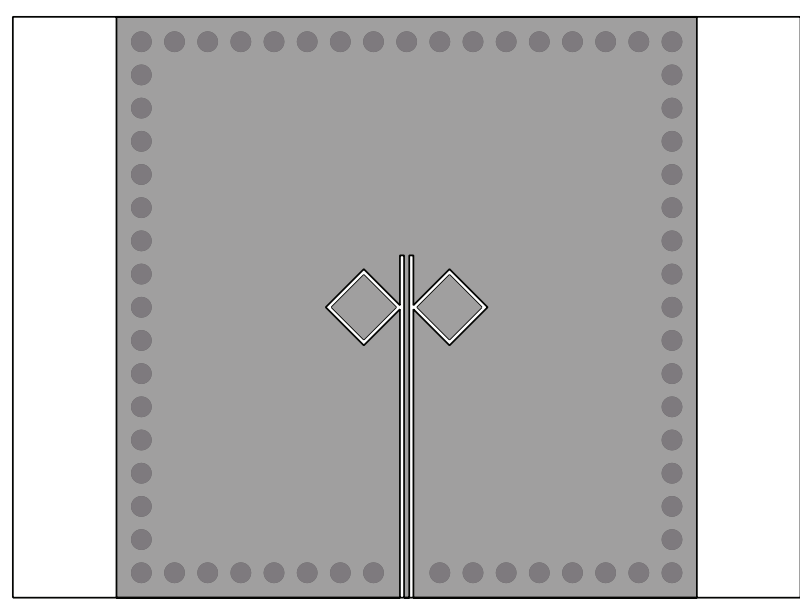

(b)

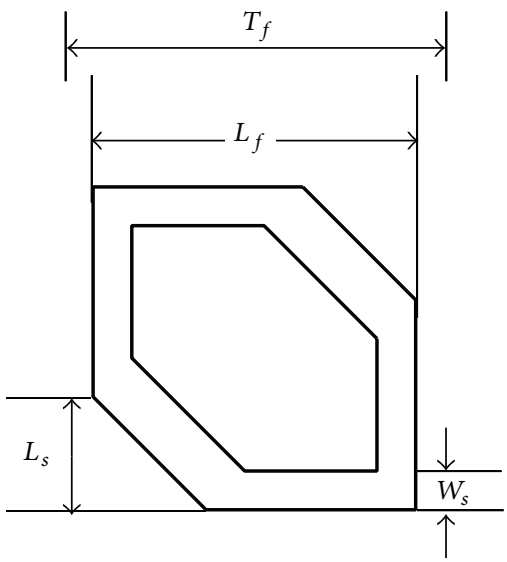

(d)

Figure 1: Antenna structure. (a) Front and side view, (b) back view, (c) detailed structure of the dual rhombic slot loop, and (d) detailed structure of the PRS cell.

The height of the F-P cavity is the whole thickness of layer \#1 and layer \#2. The thickness of layer \#1 is chosen to be $3.175 \mathrm{~mm}$ according to the datasheet of the Rogers 5880 . The hexagon loop with truncated corners is used as the PRS cell, and the details of the PRS cell are shown in Figure 1(d). The magnitudes and phases of the reflection coefficient for different truncated corner length $L_{s}$ are simulated using Ansoft HFSS. From Figure 2, it can be seen that the phases can be easily turned by changing $L_{s}$ so the resonant condition of (1) can be satisfied with proper value of $L_{s}$. Meanwhile, it can be found that the magnitudes are all higher than 0.9 at $35 \mathrm{GHz}$. According to (2), the gain enhancement would be $12.8 \mathrm{~dB}$.

Because the PRS cell is not symmetrical, an unwanted polarization wave would probably be generated when the incident wave passes through the PRS cover. When the incident wave is in $y$-polarization, the cross polarization wave would be in $x$-polarization. The generated cross polarization level is simulated and shown in Figure 3. It can be seen that the cross polarization level is under $-20 \mathrm{~dB}$ from $30 \mathrm{GHz}$ to $40 \mathrm{GHz}$, which indicates the effect of the PRS cover on the antenna cross polarization performance is little.

2.3. Metal Vias Surrounding the PRS. The antenna gain could be improved by the vias surrounding the PRS, referring to Figures 1(a) and 1(b). The distance between the metal vias and the PRS is $P$. The surrounding vias with an optimal distance $P$ could suppress the surface wave and confine the wave in the cavity as shown in Figure 4 . It can be found that the gain enhancement of $1.6 \mathrm{~dB}$ is obtained when the vias distance $P$ is $3 \mathrm{~mm}$. At this optimal distance, the sidelobes at $\theta=90^{\circ}$ are decreased and the main lobes are enhanced.

2.4. Balun from $C P W$ to Microstrip Line. Considering the PCB process, the slot width of a CPW feedline should be wider than $0.1 \mathrm{~mm}$. If the slot width $g$ of the CPW is $0.1 \mathrm{~mm}$, 


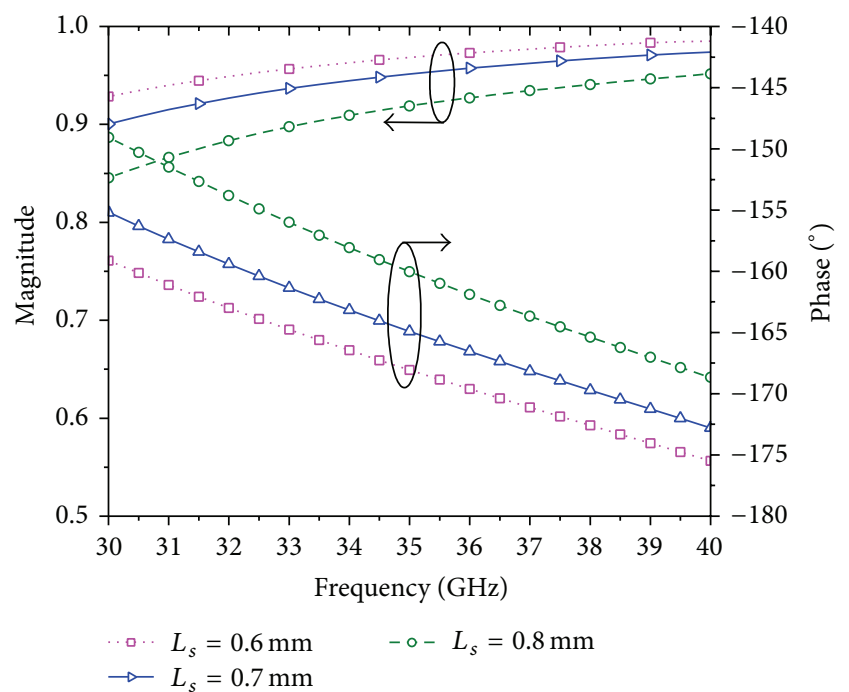

FIgURE 2: The reflection magnitudes and phases of the PRS cell.

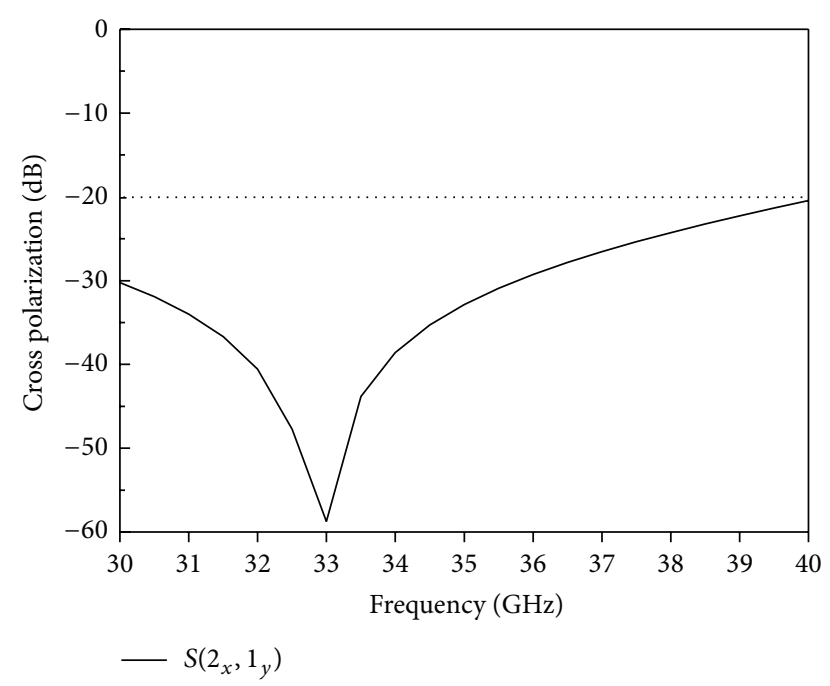

FIGURE 3: Simulated cross polarization performance of the hexagon loop PRS cell.

the width $W_{2}$ of the metal trace would be $2.3 \mathrm{~mm}$ to obtain $50 \Omega$ characteristic impedance. $W_{2}$ will be longer than a quarter of guide wavelength and this CPW will not be a TEM wave transmission line. Thus, the CPW feedline with $100 \Omega$ characteristic impedance is presented, and the trace and slot widths are $0.25 \mathrm{~mm}$ and $0.2 \mathrm{~mm}$, respectively. In order to measure the designed antenna, a balun from $100 \Omega \mathrm{CPW}$ line to $50 \Omega$ microstrip line is designed. The designed balun is printed on layer \#2. The two layers were fixed together by plastic screws after fabrication as shown in Figure 5.

The CPW-microstrip line transition reported in [21] is referred to in this antenna design. The structure of the balun that transforms the $100 \Omega \mathrm{CPW}$ feedline to the $50 \Omega$ microstrip line is shown in Figure 6. It is composed of a circular CPW with the radius of $R_{c}$, a microstrip ring with the radius of $R_{m}$, and a short-ended stub. The microstrip line

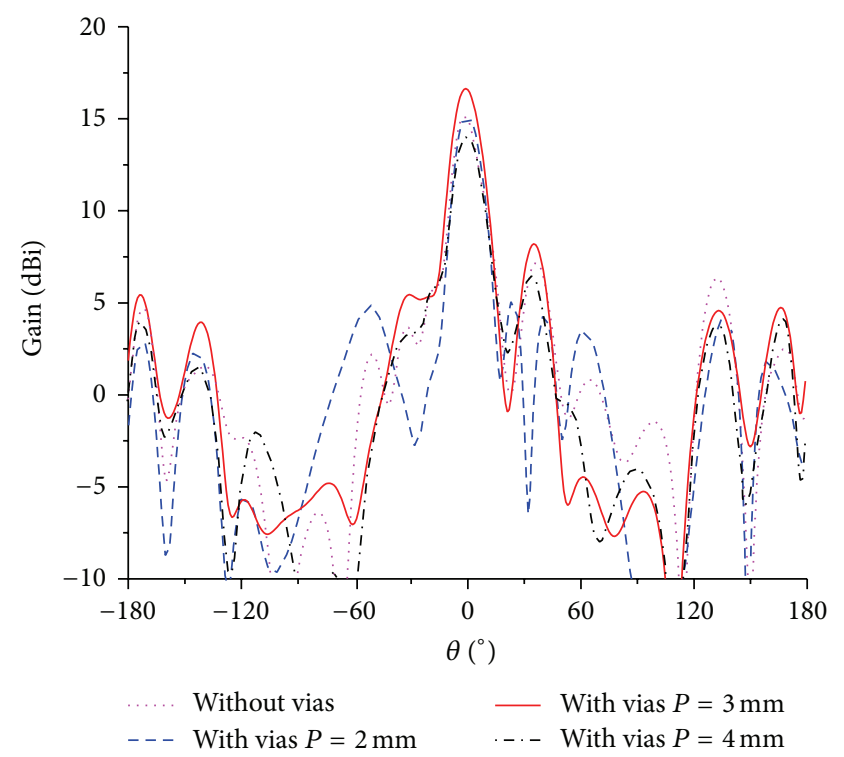

(a)

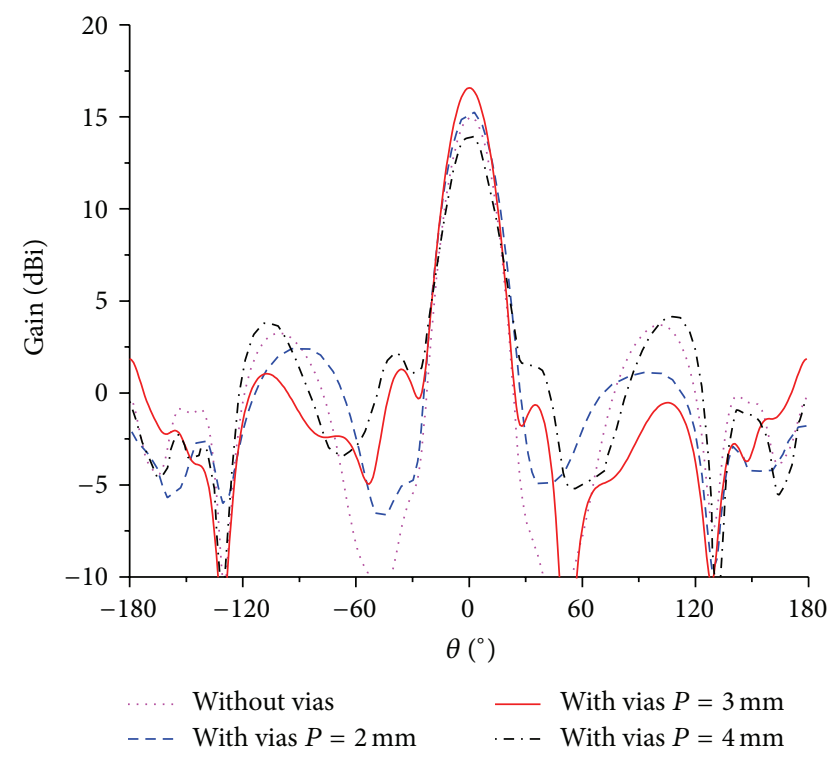

(b)

FIGURE 4: Simulated radiation patterns (a) E-plane (yoz) and (b) $\mathrm{H}$ plane (xoz) at $35 \mathrm{GHz}$.

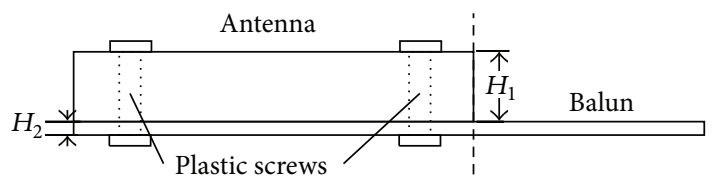

FIgURE 5: Side view of the F-P antenna and balun.

is on the top side of layer $\# 2$ with the width of $W_{50}$, whose characteristic impedance is $50 \Omega$. The CPW is on the bottom side with the same sizes of the antenna CPW feedline. The electromagnetic wave fed by the microstrip will be coupled by proximity manner by the ring of the microstrip line and the 


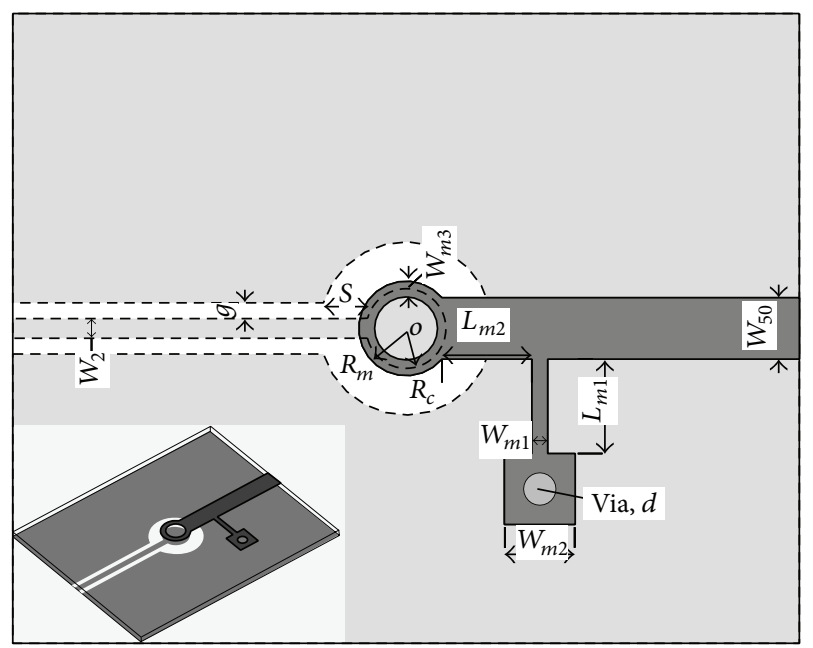

FIGURE 6: Balun structure.

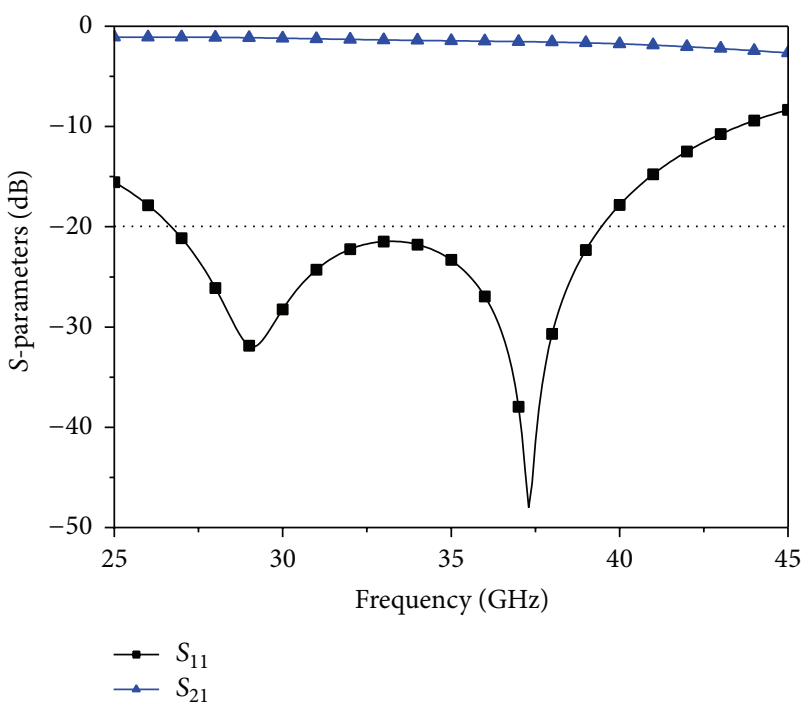

Figure 7: Simulated $S$-parameters of the balun.

ring of the CPW. A short-ended stub is shunted in parallel to the microstrip line to widen the bandwidth of the transition.

The simulated $S$-parameters of the balun are shown in Figure 7. $S_{11}$ less than $-20 \mathrm{~dB}$ is within the bandwidth from $27 \mathrm{GHz}$ to $39 \mathrm{GHz}$ and $S_{21}$ is about $-1.5 \mathrm{~dB}$, which ensures a good passband performance.

\section{Simulation and Measurement Results}

In order to validate the proposed antenna, a prototype is fabricated and tested. Figure 8 shows the photograph of the fabricated F-P antenna. The center frequency of the antenna is $35 \mathrm{GHz}$. The dual rhombic slot loops have a perimeter of $1.2 \lambda_{0}$. The metal vias surrounded area is about $3 \lambda_{0} \times 3 \lambda_{0}$ and the thickness of the antenna is $0.38 \lambda_{0}$. The geometric parameters of the antenna are listed in Table 2.

$\left|S_{11}\right|$ performance is measured by the vector network analyzer (VNA) of Agilent 8722ES. The radiation performances

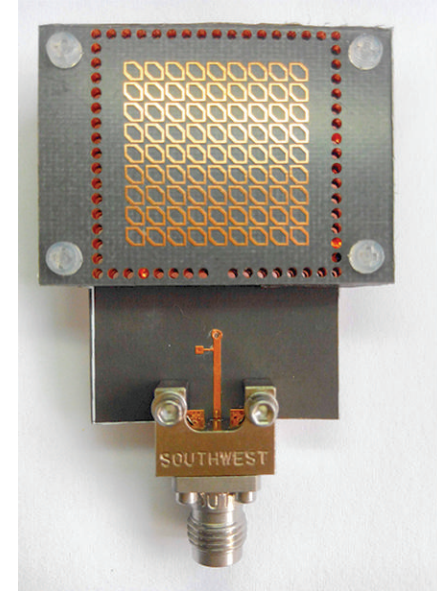

(a)

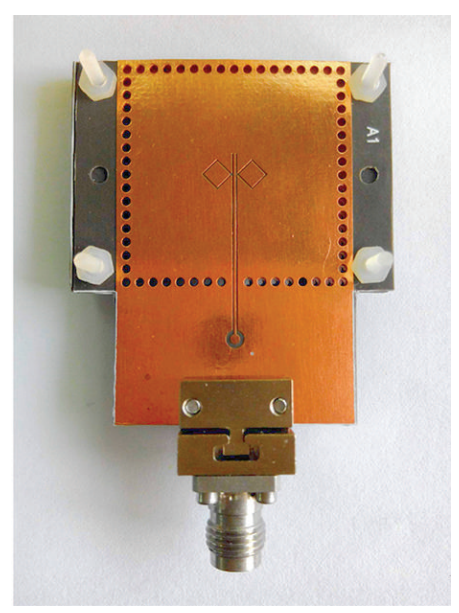

(b)

FIGURE 8: Photograph of the proposed F-P antenna. (a) Top view, (b) bottom view.

of the antenna are tested in the anechoic chamber. The radiation patterns were measured in an anechoic chamber, which is based on the NSI 2000 antenna far-field measurement system designed by Nearfield Systems Inc. The SNR (Signal-Noise Ratio) of the measurement within the required frequency band is better than $40 \mathrm{~dB}$.

The simulated and measured $\left|S_{11}\right|$ is plotted in Figure 9. The measured impedance bandwidth of $\left|S_{11}\right|$ less than $-10 \mathrm{~dB}$ is $10.5 \%(34-37.7 \mathrm{GHz})$, which is broader than that of the simulated one. This is probably induced by the manufacture method. The two substrate layers were manually clamped by four plastic screws. There is probably a thin air layer between the two substrates, which led to the bandwidth wider.

The simulated and measured gains versus frequency are shown in Figure 10. A peak gain of $15.4 \mathrm{dBi}$ is measured at $35 \mathrm{GHz}$. The $3 \mathrm{~dB}$ gain bandwidth of the F-P antenna is about $7.1 \%(33.2-35.7 \mathrm{GHz})$. The antenna gain is higher than $10 \mathrm{dBi}$ from $32.4 \mathrm{GHz}$ to $36.4 \mathrm{GHz}$. The measured and simulated gain patterns of the F-P antenna at the frequency of $35 \mathrm{GHz}$ are illustrated in Figure 11. For comparison, the gain patterns 
TABLE 2: Geometry of the F-P antenna.

\begin{tabular}{ccccccccccccccccccccccccccc}
\hline$L$ & $W$ & $D$ & $T$ & $T_{f}$ & $L_{f}$ & $L_{s}$ & $W_{s}$ & $L_{1}$ & $W_{1}$ & $L_{2}$ & $W_{2}$ & $g$ & $W_{50}$ & $L_{m 1}$ & $W_{m 1}$ & $L_{m 2}$ & $W_{m 2}$ & $W_{m 3}$ & $R_{c}$ & $R_{m}$ & $d$ & $S$ & $H_{1}$ & $H_{2}$ & $P$ \\
\hline 28 & 38 & 1 & 1.6 & 2.2 & 2 & 0.7 & 0.24 & 2.6 & 0.2 & 2.4 & 0.25 & 0.2 & 0.78 & 1.2 & 0.2 & 1.14 & 0.9 & 0.2 & 0.55 & 0.6 & 0.4 & 0.55 & 3.15 & 0.254 & 3 \\
\hline
\end{tabular}

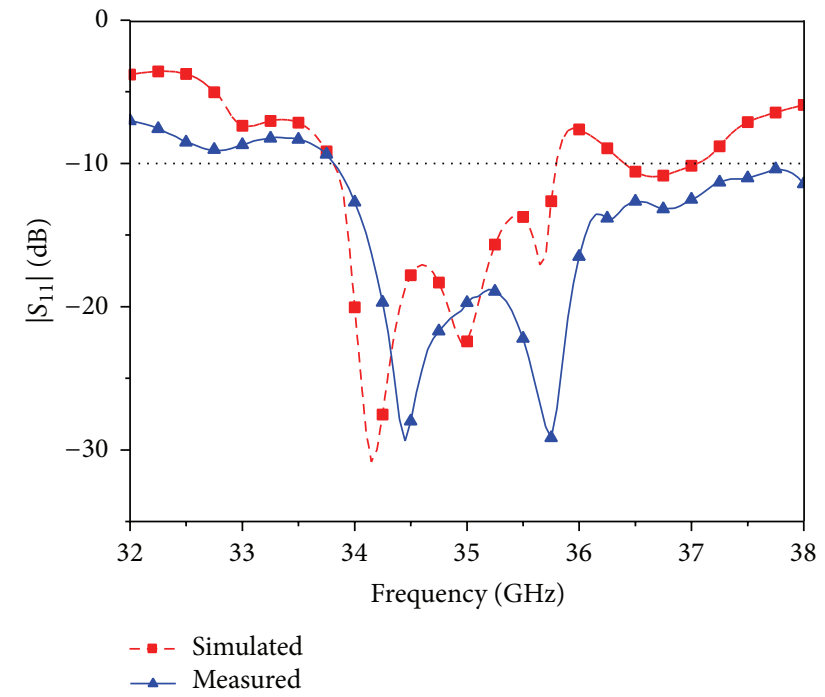

FIgURE 9: Simulated and measured $S$-parameters.

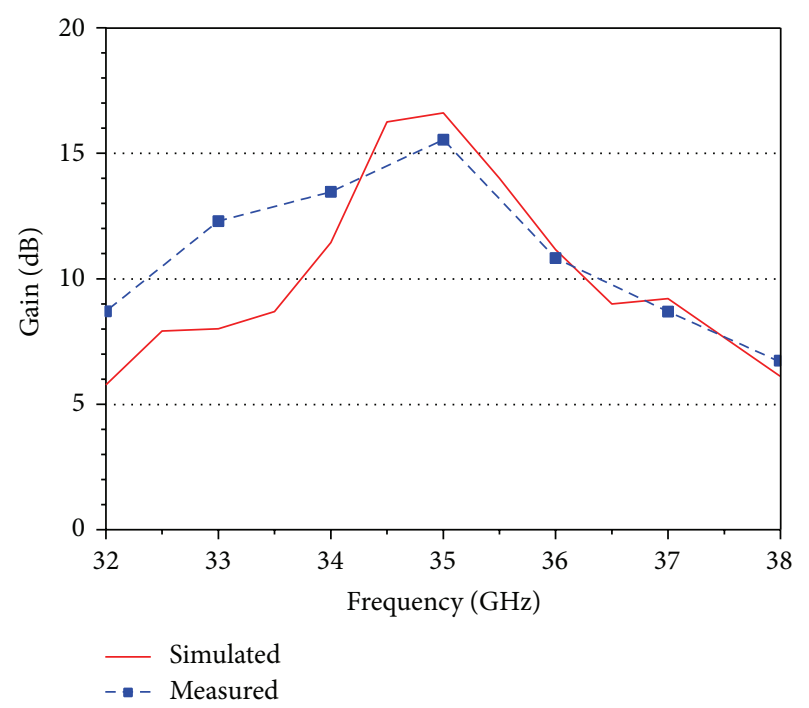

FIGURE 10: Simulated and measured gains.

of the primary feeding antenna are plotted, too. The primary antenna has a bidirectional radiation pattern and the gain in the broadside is only $6.1 \mathrm{dBi}$. When the PRS is covered above the primary antenna, the sidelobe at $\theta=90^{\circ}$ and the back radiation of the primary feeding antenna in the $\mathrm{H}$-plane are suppressed and the gain of the F-P antenna is increased by $10.5 \mathrm{~dB}$. The measured sidelobe level is $-9.5 \mathrm{~dB}$ and the frontto-black ratio is $11.5 \mathrm{~dB}$.

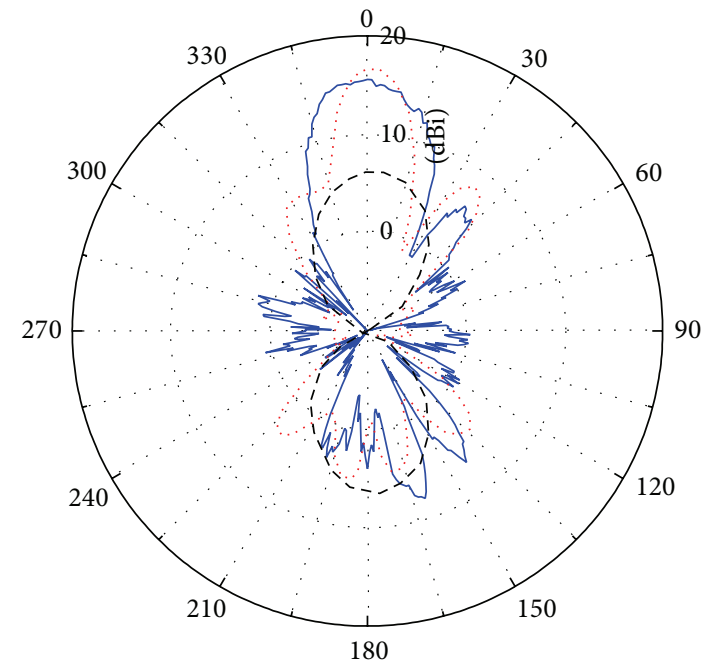

Simulated_F-P antenna

Measured_F-P antenna

- - - Simulated_Active antenna

(a)

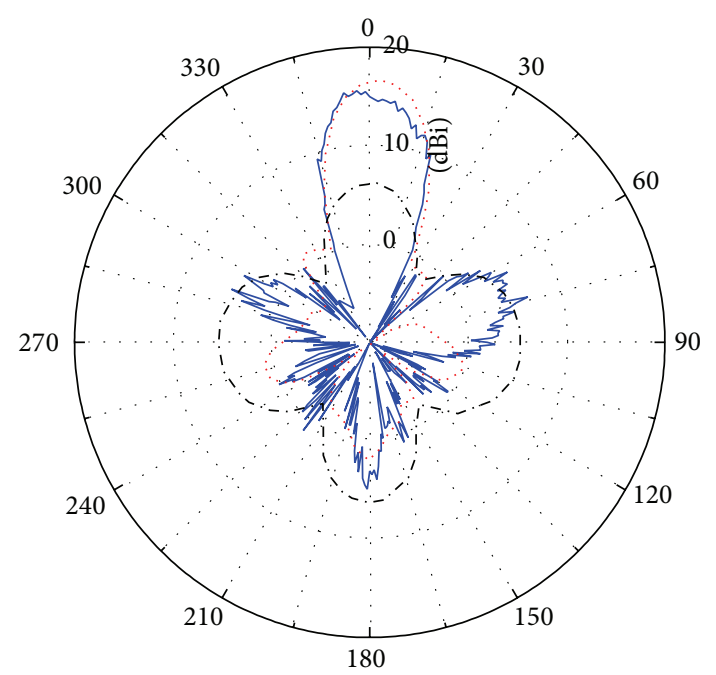

Simulated_F-P antenna

- Measured_F-P antenna

. - - Simulated_Active antenna

(b)

FIGURE 11: Measured and simulated radiation patterns of (a) E-plane (yoz) and (b) H-plane (xoz) at $35 \mathrm{GHz}$.

\section{Conclusion}

A novel millimeter wave F-P antenna fed by CPW with high gain, broad gain bandwidth, and low profile has been 
proposed. The vias surrounding the PRS are used to improve the gain. A CPW-to-microstrip transition has been designed to measure the antenna's performance and expend the applications. The substrate layer was used to design the F-P cavity to lower the profile and strengthen the antenna structure. The measured results show that the bandwidth of $\left|S_{11}\right|$ less than $-10 \mathrm{~dB}$ is $10.5 \%(34-37.7 \mathrm{GHz})$ and the bandwidth of $3 \mathrm{~dB}$ gain is $7.1 \%(33.2-35.7 \mathrm{GHz})$. A peak gain of $15.4 \mathrm{dBi}$ is obtained at the center frequency of $35 \mathrm{GHz}$. The proposed antenna can be fabricated by using only one integrated substrate in mass production. With the characteristics of broadband, high gain, low profile, robust structure, and easy integration, this F-P antenna can be used in the millimeter wave communication systems and applied as the receiving antenna of the wireless power transmission systems.

\section{Competing Interests}

The authors declare that there are no competing interests regarding the publication of this paper.

\section{Acknowledgments}

This work was supported by Natural Science Foundation of China under Grant no. 61271062.

\section{References}

[1] A. Ghosh, T. A. Thomas, M. C. Cudak et al., "Millimeterwave enhanced local area systems: a high-data-rate approach for future wireless networks," IEEE Journal on Selected Areas in Communications, vol. 32, no. 6, pp. 1152-1163, 2014.

[2] N. Valliappan, A. Lozano, and R. W. Heath, "Antenna subset modulation for secure millimeter-wave wireless communication," IEEE Transactions on Communications, vol. 61, no. 8, pp. 3231-3245, 2013.

[3] T. Bai, A. Alkhateeb, and R. W. Heath, "Coverage and capacity of millimeter-wave cellular networks," IEEE Communications Magazine, vol. 52, no. 9, pp. 70-77, 2014.

[4] W. Hong, K.-H. Baek, Y. Lee, Y. Kim, and S.-T. Ko, "Study and prototyping of practically large-scale mmWave antenna systems for 5G cellular devices," IEEE Communications Magazine, vol. 52, no. 9, pp. 63-69, 2014.

[5] T. S. Rappaport, S. Sun, R. Mayzus et al., "Millimeter wave mobile communications for 5G cellular: it will work!", IEEE Access, vol. 1, pp. 335-349, 2013.

[6] N. Shinohara, "Recent wireless power transmission via microwave and millimeter-wave in Japan," in Proceedings of the 42nd European Microwave Conference (EuMC '12), pp. 1347-1350, Amsterdam, Netherlands, 2012.

[7] W. Hu, M. Arrebola, R. Cahill et al., "94 GHz dual-reflector antenna with reflectarray subreflector," IEEE Transactions on Antennas and Propagation, vol. 57, no. 10, pp. 3043-3050, 2009.

[8] G. Von Trentini, "Partially reflecting sheet arrays," IRE Transactions on Antennas and Propagation, vol. 4, no. 4, pp. 666-671, 1956.

[9] R. Gardelli, M. Albani, and F. Capolino, "Array thinning by using antennas in a Fabry-Perot cavity for gain enhancement," IEEE Transactions on Antennas and Propagation, vol. 54, no. 7, pp. 1979-1990, 2006.
[10] A. R. Weily, K. P. Esselle, T. S. Bird, and B. C. Sanders, "Dual resonator 1-D EBG antenna with slot array feed for improved radiation bandwidth," IET Microwaves, Antennas \& Propagation, vol. 1, no. 1, pp. 198-203, 2007.

[11] C. Mateo-Segura, A. P. Feresidis, and G. Goussetis, "Bandwidth enhancement of 2-D leaky-wave antennas with double-layer periodic surfaces," IEEE Transactions on Antennas and Propagation, vol. 62, no. 2, pp. 586-593, 2014.

[12] W. Naizhi, L. Qiang, W. Changying, L. Talbi, Z. Qingsheng, and X. Jiadong, "Wideband Fabry-Perot resonator antenna with two complementary PRS layers," IEEE Transactions on Antennas and Propagation, vol. 62, no. 5, pp. 2463-2471, 2014.

[13] R. Sauleau, P. Coquet, and T. Matsui, "Low-profile directive quasi-planar antennas based on millimetre wave Fabry-Perot cavities," IEE Proceedings-Microwaves, Antennas and Propagation, vol. 150, no. 4, pp. 274-278, 2003.

[14] Y. Lee, X. Lu, Y. Hao, S. Yang, J. R. G. Evans, and C. G. Parini, "Low-profile directive millimeter-wave antennas using free-formed three-dimensional (3-D) electromagnetic bandgap structures," IEEE Transactions on Antennas and Propagation, vol. 57, no. 10, pp. 2893-2903, 2009.

[15] G. N. Tan, X. X. Yang, H. G. Xue, and Z.-L. Lu, "A dual-polarized Fabry-Perot cavity antenna at Ka band with broadband and high gain," Progress in Electromagnetics Research C, vol. 60, pp. 179186, 2015.

[16] A. Hosseini, F. Capolino, and F. De Flaviis, "Gain enhancement of a V-band antenna using a Fabry-Pérot cavity with a selfsustained all-metal cap with FSS," IEEE Transactions on Antennas and Propagation, vol. 63, no. 3, pp. 909-921, 2015.

[17] A. P. Feresidis, G. Goussetis, S. Wang, and J. C. Vardaxoglou, "Artificial magnetic conductor surfaces and their application to low-profile high-gain planar antennas," IEEE Transactions on Antennas and Propagation, vol. 53, no. 1, pp. 209-215, 2005.

[18] Y. Sun, Z. N. Chen, Y. Zhang, H. Chen, and T. S. P. See, "Subwavelength substrate-integrated Fabry-Pérot cavity antennas using artificial magnetic conductor," IEEE Transactions on Antennas and Propagation, vol. 60, no. 1, pp. 30-35, 2012.

[19] W. Liu, Z. N. Chen, T. S. P. See, and F. Liu, "SIW-slot-fed thin beam-squint-free fabry-pérot cavity antenna with low backlobe levels," IEEE Antennas and Wireless Propagation Letters, vol. 13, pp. 552-554, 2014.

[20] S. A. Hosseini, F. Capolino, and F. De Flaviis, "Q-band singlelayer planar fabry-pérot cavity antenna with single integratedfeed," Progress In Electromagnetics Research C, vol. 52, pp. 135144, 2014.

[21] T. Ziwen, W. Jianpeng, and D. Yan, "Design of broadband microstrip-to-CPW transition," Electronics Letters, vol. 50, no. 1, pp. 35-37, 2014. 


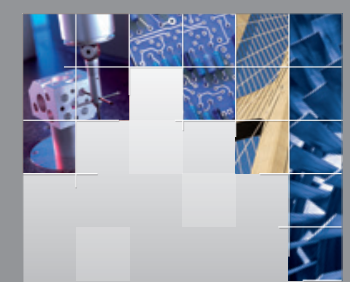

\section{Enfincering}
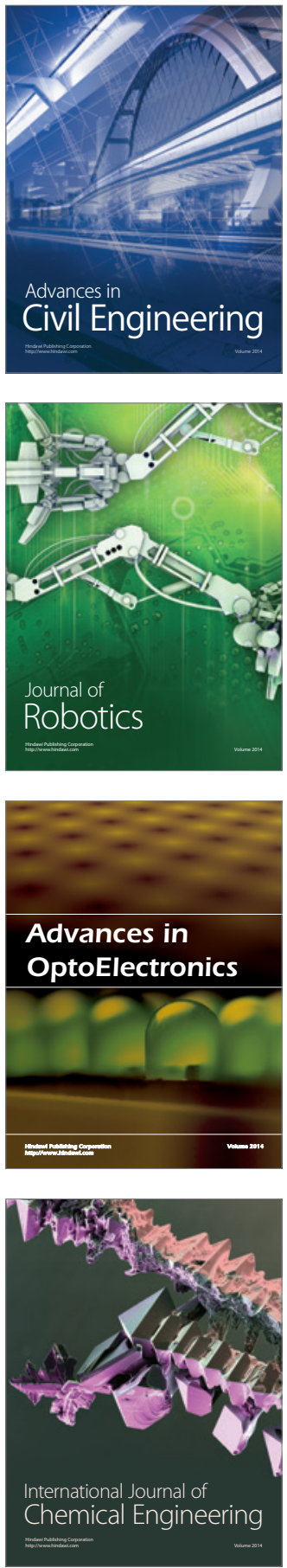

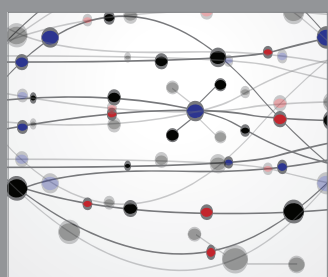

The Scientific World Journal

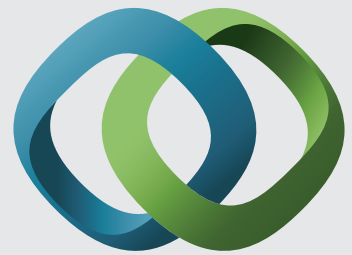

\section{Hindawi}

Submit your manuscripts at

http://www.hindawi.com
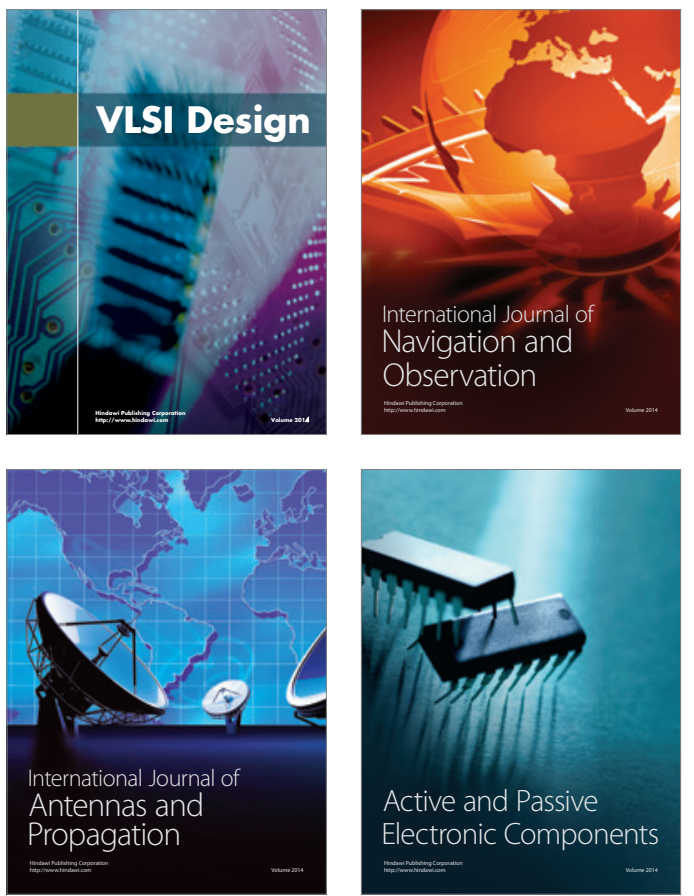
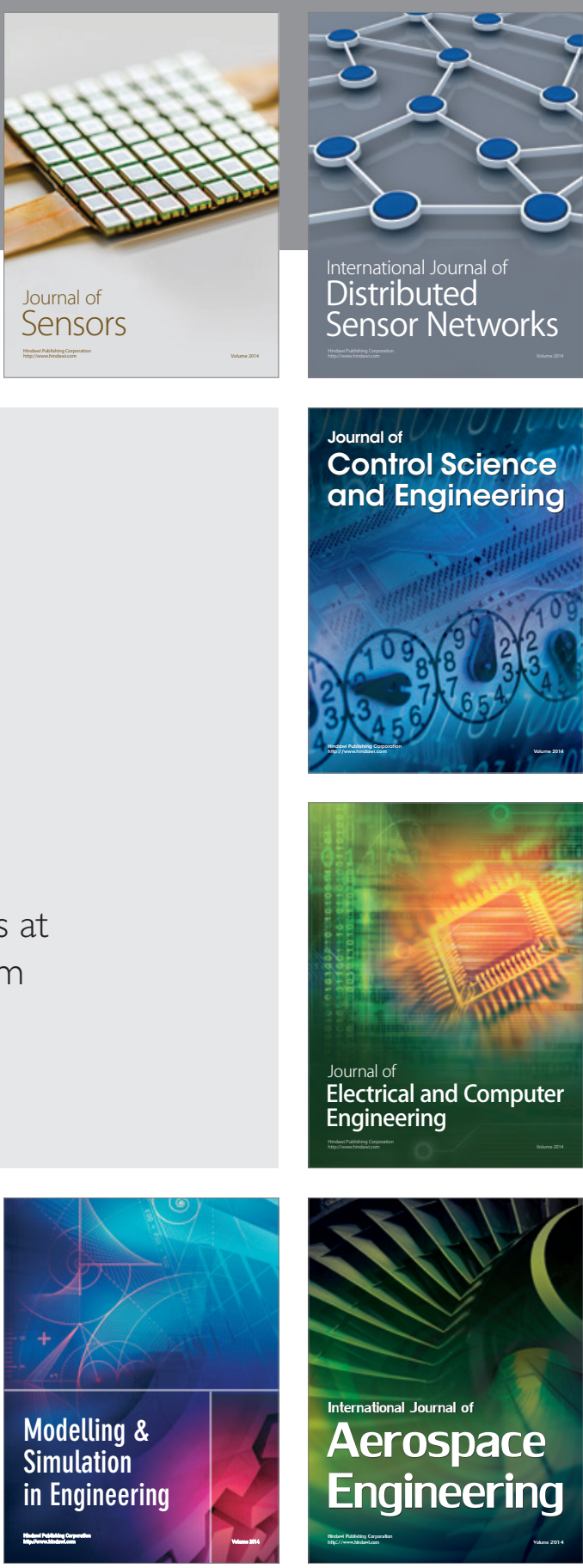

International Journal of

Distributed

Sensor Networks

Journal of

Control Science

and Engineering
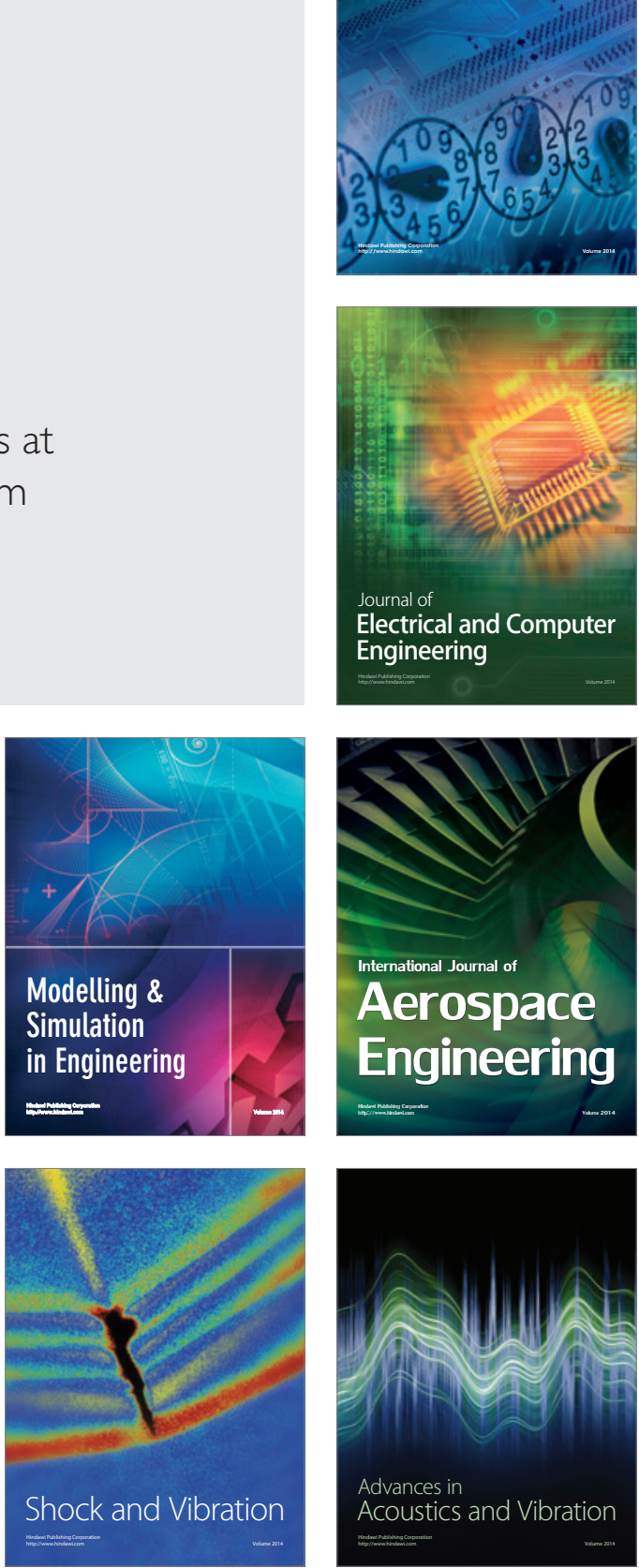